\title{
How common is oral lichen planus?
}

\author{
What is the prevalence of oral lichen planus?
}

\section{McCartan BE, Healy CM.}

The reported prevalence of oral lichen planus: a review and critique. J Oral Pathol Med 2008; 37:447-453

Data sources Medline and ISI Web of Science were searched, along with references of identified papers.

Study selection Studies reporting the prevalence or incidence of oral lichen planus (OLP) were included.

Data extraction and synthesis Papers were examined for five criteria: use of a clinic- or population-based study; adequate demographic description (by sex and age group) of the population; adequate demographic description of the sample (if the population was sampled); adequate demographic description of the OLP cases identified; and histological confirmation of the clinical diagnosis.

Results Forty-five relevant papers were identified, of which 21 were clinic-based and 24 were population studies. All but one of the population studies was deficient. The one remaining study, while having some defects, was probably of sufficient quality to make its findings useful. An overall age-standardised prevalence of $1.27 \%$ (0.96\% in men and $1.57 \%$ in women) can be calculated from this study.

Conclusions Only one of the studies identified for the review contained sufficient detail about its methods and of its findings to enable an estimate of population prevalence to be calculated. This did not distinguish between OLP and lichenoid reactions, however. Further, welldesigned, studies with using standardised methods and criteria, are required in a number of different populations.
Address for correspondence: Claire M Healy, Division of Oral and Maxillofacial Surgery, Oral Medicine and Oral Pathology, School of Dental Science, Trinity College, Dublin, Ireland. E-mail: claire.healy@dental.tcd.ie

\section{Commentary}

OLP is not only supposed to be one of the most common inflammatory diseases that involve the oral mucosa but it is also considered to be a potentially premalignant disorder. More than 30 years ago, it was stated that oral cancer and precancer should be given priority in dental epidemiological studies because they are considered "significant health problems." 1 This review by McCartan and Healy attempts to address whether there is substantial evidence about the prevalence of OLP and also allows us to check what epidemiological data have been reported on oral mucosal diseases other than cancer.

The paper in fact helps to highlight the relative paucity of highquality epidemiological studies worldwide on the prevalence of OLP, and therefore the need for well-designed studies to be carried out. Particularly noteworthy is the advice to distinguish OLP from socalled oral lichenoid lesions (OLL) in future work. There is indeed a spectrum of OLP-like lesions that may confuse the differential diagnosis and affect the results of epidemiological studies. A recent international consensus has proposed the classification of OLL into lichenoid contact lesions, lichenoid drug reactions and lichenoid lesions of graft-versus-host disease. ${ }^{2}$ Only one study included in the review attempted to report the prevalence of OLL but it is unclear how those lesions were differentiated from OLP.

The difficulty in distinguishing OLP from OLL in prevalence studies has certainly deeply influenced the results. The review also failed to provide a comprehensive, unbiased summary of current evidence on the prevalence of OLP because of its vague methods. One of the main weaknesses is that the search strategies used may have been inadequate: apparently some relevant papers were missed. ${ }^{3-10}$ This was probably because of too-selective search terms instead of more generic ones for example "oral precancerous condition/ lesion, oral mucosal lesions/ diseases". Some of the missing articles may have been excluded (perhaps because they were published in a language other than English, or recruited very selected populations) but the inclusion and exclusion criteria were not clearly stated. Another negative property of the review is the lack of clarity about the diagnostic criteria used to select the papers. Indeed, the authors selected only two kinds of studies (clinic- and population-based) but, if they considered mandatory a histological verification of the clinical diagnosis, then biopsy-based surveys should also have been considered. ${ }^{11}$

Moreover, no real quality assessment of the included primary studies was carried out. As a result, the reader cannot see why the authors consider only one study to have an acceptable dataset. Notably, a robust systematic review on the world prevalence of oral leukoplakia, ${ }^{12}$ which shares a number of references with this review, considered the majority to be of sufficient quality to be pooled. A prevalence estimate was then calculated using a statistical approach that gives different weight to the various studies, according to their level of precision. 
Because of all the above problems, it is ultimately also difficult to understand if the studies used for the calculation of age-standardised data were the only five worthy of inclusion.

In conclusion, this paper usefully suggests the need for more welldesigned epidemiological studies on OLP with standardised methods and diagnostic criteria able to distinguish OLP from OLL. The paucity of such suitable studies and the lack of a real systematic approach to the topic did not, in this case, allow the formulation of a strong evidence-based answer to the original query.

\section{Marco Carrozzo}

Department of Oral Medicine, School of Dental Sciences, University of Newcastle upon Tyne, Newcastle upon Tyne, UK

1. Kleinman DV, Swango PA, Pindborg J], Gupta P. Toward assessing trends in oral mucosal lesions: lessons learned from oral cancer. Adv Dent Res 1993; 7:32-41.

2. Al-Hashimi I, Schifter M, Lockhart PB, et al. Oral lichen planus and oral lichenoid lesions: diagnostic and therapeutic considerations. Oral Surg Oral Med Oral Pathol Oral Radiol Endod 2007; 103 (suppl.):S25:e1-12.

3. Ramírez-Amador VA, Esquivel-Pedraza L, Orozco-Topete R. Frequency of oral conditions in a dermatology clinic. Int J Dermatol 2000; 39:501-505.

4. Pearson N, Croucher R, Marcenes W, O'Farrell M. Prevalence of oral lesions among a sample of Bangladeshi medical users aged 40 years and over living in Tower Hamlets, UK. Int Dent J 2001; 51:30-34.
5. Nagao T, Warnakulasuriya S, Gelbier S, Yuasa H, Tsuboi S, Nakagaki H. Oral pre-cancer and the associated risk factors among industrial workers in Japan's overseas enterprises in the UK. J Oral Pathol Med 2003; 32:257-264.

6. Harris CK, Warnakulasuriya KA, Cooper DJ, Peters TJ, Gelbier S. Prevalence of oral mucosal lesions in alcohol misusers in south London. J Oral Pathol Med 2004; 33:253-259.

7. dos Santos PJ, Bessa CF, de Aguiar MC, do Carmo MA. Cross-sectional study of oral mucosal conditions among a central Amazonian Indian community, Brazil. J Oral Pathol Med 2004; 33:7-12.

8. Bornstein MM, Lüönd-Valeskeviciute I, Altermatt HJ, Stauffer E, Buser D. [Oral mucosal lesions diagnosed in a stomatology service. An examination of clinico-pathological findings from the year 2003.] Schweiz Monatsschr Zahnmed 2006; 116:468-475.

9. Jáhn M, Schmidt ], Fejérdy L, Tollas OL, Fejérdy P, Madléna M. [The prevalence of oral mucosal lesions in Hungary.] Fogorv Sz 2007; 100:59-63.

10. Scheifele C, Nassar A, Reichart PA. Prevalence of oral cancer and potentially malignant lesions among shammah users in Yemen. Oral Oncol 2007; 43:42-50.

11. Corrêa L, Frigerio ML, Sousa SC, Novelli MD. Oral lesions in elderly population: a biopsy survey using 2250 histopathological records. Gerodontology 2006 23:48-54.

12. Petti S. Pooled estimate of world leukoplakia prevalence: a systematic review. Oral Oncol 2003; 39:770-780.

Evidence-Based Dentistry (2008) 9, 112-113. doi:10.1038/sj.ebd.6400614 